\title{
PATTERN OF ALCOHOL USE AND ITS EFFECTS IN RELATION TO THE AGE OF INITIATION OF ALCOHOL USE AMONG THE RESIDENTS OF JHAUKHEL AREA OF BHAKTAPUR DISTRICT
}

\author{
Soman Gurung, Ravi Kant Gupta, Vinutha Silvanus
}

Department of Community Medicine, Nepal Medical College, Attarkhel, Gokarneshwor-8, Kathmandu, Nepal

\section{ABSTRACT}

Over the past few decades, alcohol consumption has increased in quantity and frequency. Several studies have suggested that people who start drinking at younger age have an increased risk of alcohol use disorder. This study was carried out to assess the pattern of alcohol consumption in relation to the age of initiation of alcohol use among the residents of Jhaukhel area of Bhaktapur district. A cross sectional descriptive survey was conducted in Jhaukhel area of Bhaktapur district among the permanent residents aged 15 years and above through a purposive sampling technique using a pre tested self-constructed proforma. Assessment of alcohol use, harmful/ hazardous drinking and alcohol dependence was done using an AUDIT questionnaire as a tool. Chi-square test and Fisher's exact test were applied and 'p' value was calculated to see the association between age of onset of alcohol use and the alcohol use pattern and effects. The level of significance was set at $5 \%$, and 'p' value of $<0.05$ was considered statistically significant. A total of 190 respondents were interviewed. Mean age of the respondents was $41.25 \pm 16.4$ years while mean age of initiation of alcohol consumption was $20 \pm 4.3$ years and 31 (30.4\%) of drinkers initiated alcohol consumption before legal drinking age (18 years). This was more among males (36.5\%) than females (14.3\%), (p-value: 0.03, OR: 3.4, 95\%CI: 1-11) Initiating alcohol consumption early in life before 18 years was strongly associated with binge drinking pattern ( $\mathrm{P}$ value: <0.001, OR: 9.5, 95\%CI: 2.7-33.3). Those who initiate drinking before 18 years were more likely to suffer from alcohol related medical problems compared to those who initiated drinking after 18 years (OR: 6.63, 95\% CI: 2.3-19.3, P value: 0.001). Parental consumption of alcohol was found to be associated with the early initiation of alcohol use (OR: 2.7, 95\%CI: 1.01-6.96, P value: 0.03). Early initiation of alcohol consumption before legal drinking age was not only a predictor for binge drinking and alcohol dependence, but also a risk factor for alcohol related medical problem, accidents and self-inflicted injuries. Hence this is a serious issue which needs to be addressed at the individual, family as well as community level.

\section{KEYWORDS}

Jhaukhel, Age of onset of alcohol use, Binge drinking, Moderate to hazardous drinking, Alcohol dependence

Received on: July 30, 2021

Accepted for publication: November 05, 2021

\section{CORRESPONDING AUTHOR}

Dr. Soman Gurung

Department of Community Medicine

Nepal Medical College,

Attarkhel, Gokarneshwor-8, Kathmandu, Nepal

Email: gurungsoman0971@gmail.com

Orcid No: https://orcid.org/0000-0001-7481-8065

DOI: https://doi.org/10.3126/nmcj.v23i4.42228 


\section{INTRODUCTION}

Alcohol is a psychoactive substance with dependence producing properties that has been used in many cultures for centuries. It is one of the most widely used substances in many parts of the world as drinking during social gatherings. ${ }^{1}$ Harmful alcohol use is a worldwide social and medical problem. Over the past 30 to 40 years, alcohol consumption has increased in quantity and frequency. The age at which people start drinking has also declined. The population groups at great risk are those undergoing rapid socio-economic and cultural changes; they view alcohol as a symbol of prestige and social status. ${ }^{2}$ The harmful use of alcohol ranks among the top five risk factor for diseases, disability and death throughout the world and is a causal factor in more than 200 diseases and injury condition. It can also result in harm to other people such as family member, friends, co-workers and strangers. Worldwide, 3.3 million deaths every year results from harmful use of alcohol, this represent $5.9 \%$ of all death. ${ }^{1}$

Today, hardly any society is spared of alcohol use, and Nepal is no exception. ${ }^{3}$ According to 'Non-communicable disease risk factor: STEPS Survey in Nepal (2014)' $73.5 \%$ were life time abstainer, $4.5 \%$ were 12 month abstainer and $17.4 \%$ were drinking within last 30 days. ${ }^{4}$ The most alarming fact is that people are beginning to drink at increasingly younger age over the past few decades. The average age of initiation of alcohol use has reduced from 28 years during 1980s to 17 years in 2007 according to the report from systematic analysis for the global burden of disease study $(2010) .{ }^{5}$ Several studies have suggested that people who start drinking at younger age have an increased risk of alcohol use disorder ${ }^{6,7}$ Early drinking onset would also lead to unintentional injuries, motor vehicle crashes, physical fights, and unplanned/ unprotected sex after an episode of heavy drinking and nicotine dependence, antisocial personality, academic underachievement, conduct disorder, illicit substance use in long run. ${ }^{8}$ However Nepal has very limited studies reflecting the association of age of initiation of alcohol use and alcohol use disorder. Hence the main objective of this study was to study the epidemiology of alcohol use, alcohol use pattern and its effects in relation with the age of initiation of alcohol use among the residents of Jhaukhel area of Bhaktapur district.

\section{MATERIALS AND METHODS}

This is a descriptive cross sectional study conducted in Jhaukhel area of Bhaktapur district from February 2018 to October 2018 among the permanent residents of Jhaukhel aged 15 years and above through a purposive sampling technique. Total 190 respondents from 70 household were interviewed face to face through a door to door survey after taking an informed written consent. Age of initiation of alcohol consumption was taken as an independent variable and was categorised as: onset of alcohol use 'Before 18 years' and 'After 18 years'. Assessment of alcoholism, harmful/ hazardous drinking and alcohol dependence was done using an 'Alcohol Use Disorder Identification Test' (AUDIT) questionnaire as a tool, where AUDIT score of 8 or more was considered as harmful/hazardous drinking and score of $>19$ was indicated as alcohol dependence. ${ }^{9}$

Data on alcohol consumption: Pattern of alcohol use and abuse were defined as: (a). Lifetime drinker/Ever used alcohol: Those who had ever consumed or had at least one alcoholic drink in their lives, (b). Life-time abstainer: Those who have never consumed alcohol in their life-time, (c) Current drinker: Those who had consumed alcoholic drink in last 12 month, (d) Binge drinker: Those who consumed at least five alcoholic drink on a single occasion during the past 30 days. The unit of measurement for the drinks specified in this study was a small cup of tea glass which holds approximately $150-200 \mathrm{ml}$ volume, but several units of other sizes like can of beer, glass wine, rice wine container or a cup of un-recorded home-brewed drinks were also accepted in answer to the question. Amount of alcohol consumed by the respondent were recorded based on 'Standard drink' which was calculated using the formula: Amount of drink consumed in litre $\mathrm{x}$ percent of alcohol $\mathrm{x} 0.789$ (0.789 is the specific gravity of ethyl alcohol). For this purpose, respondents were asked about the amount of alcohol they consumed in ml, which was converted in litres and was manually calculated using the formula to obtain the actual standard drink.

Statistical analysis: Data was collected, compiled and analysed using SPSS (Statistical package for Social Science) version 16. The prevalence of alcohol consumption was reported as percentage with 95\% C.I. Chisquare test and Fisher's exact test were applied and 'p' value was calculated to see the association between age of onset of alcohol use and pattern of alcohol use and effects. The level of significance was set at $5 \%$, and ' $p$ ' value of < 0.05 was considered statistically significant.

\section{RESULTS}

More than half of the respondents (53.7\%) had ever consumed alcohol, majority were the male $(74.7 \%)$ out-numbering their female counterpart (30.8\%). Lifetime abstainers 
were $46.3 \%$ (Male: 28.4\%, Female: $71.59 \%$ ). Prevalence of current drinker was found to be 45.8\% (Male: 69.7\%, Female: 19.8\%). Almost one third (34.2\%) had consumed alcohol within past 30 days (Male: 57.6\%, Female: 8.8\%). Alcohol consumption habit was found to be significantly associated with gender (p-value: $<0.001$ ), where male were 6.7 times more likely to consume alcohol than female (95\% C.I: 3.528-12.573). Similarly male had higher odds of being current drinker (p-value: <0.001, OR: 9.33, 95\% C.I: 4.7-18.2) than female. Male were also more likely to drink within past 30 days than female (p-value: <0.001, OR: $14.08,95 \%$ C.I: 6.15-32.22) (Table 1).
Mean age of the respondent was $41.25 \pm 16.4$ years and mean age of initiation of drinking was $20 \pm 4.3$ years. Among the drinkers, 30.4\% had initiated consuming alcohol before legal drinking age (18years), more were among males (36.5\%) than females (14.3\%), (p-value: 0.03, OR: 3.4, 95\%CI: 1-11) (Table 2). Early initiation of alcohol use was found to be associated with parental consumption of alcohol, hence parents consuming alcohol at home would stand as an influencing factor for the drinker to initiate drinking at an early age (p-value: 0.03 , OR: 2.7 , 95\%CI: 1.01-6.9) (Table 3).

Half of the drinker of past 30 days reported binge drinking pattern which was also found

\begin{tabular}{|c|c|c|c|c|c|c|}
\hline \multirow{2}{*}{ Gender } & \multicolumn{3}{|c|}{ Ever consumed alcohol } & \multirow{2}{*}{$\begin{array}{l}\text { Chi square } \\
\text { value }\end{array}$} & \multirow{2}{*}{ P-value } & \multirow{2}{*}{$\begin{array}{c}\text { OR } \\
(95 \% \text { C.I })\end{array}$} \\
\hline & Yes. n (\%) & No. $\mathbf{n}(\%)$ & Total (N) & & & \\
\hline Male & $74(74.7)$ & $25(25.3)$ & 99 & \multirow{3}{*}{36.9} & \multirow{3}{*}{$<0.001$} & \multirow{3}{*}{$\begin{array}{c}6.7 \\
(3.5-12.6)\end{array}$} \\
\hline Female & $28(30.8)$ & $63(69.2)$ & 91 & & & \\
\hline Total & $102(53.7)$ & $88(46.3)$ & 190 & & & \\
\hline \multicolumn{4}{|c|}{ Current Drinking } & \multirow{5}{*}{47.5} & \multirow{5}{*}{$<0.001$} & \multirow{10}{*}{$\begin{array}{c}14 \\
(6.1-32.2)\end{array}$} \\
\hline & Yes. n (\%) & No. n (\%) & Total (N) & & & \\
\hline Male & $69(69.7)$ & $30(30.3)$ & 99 & & & \\
\hline Female & $18(19.8)$ & $73(80.2)$ & 91 & & & \\
\hline \multirow[t]{3}{*}{ Total } & $87(45.8)$ & $103(54.2)$ & 190 & & & \\
\hline & \multicolumn{3}{|c|}{ Drinking within past 30 days } & \multirow{5}{*}{50.1} & \multirow{5}{*}{$<0.001$} & \\
\hline & Yes. n (\%) & No. n (\%) & Total (N) & & & \\
\hline Male & $57(57.6)$ & $42(42.4)$ & 99 & & & \\
\hline Female & $8(8.8)$ & $83(91.2)$ & 91 & & & \\
\hline Total & $65(34.2)$ & $125(65.8)$ & 190 & & & \\
\hline
\end{tabular}

Table 2: Gender wise distribution of initiation of alcohol use.

\begin{tabular}{|lccccccc|} 
Sex & $\begin{array}{c}\text { Initiating drinking } \\
\text { Before legal } \\
\text { age n (\%) }\end{array}$ & $\begin{array}{c}\text { After legal age } \\
(\geq \mathbf{1 8} \text { years) } \mathbf{n}(\%)\end{array}$ & $\begin{array}{c}\text { Total } \\
\text { (N) }\end{array}$ & $\begin{array}{c}\text { Fishers } \\
\text { exact } \\
\text { value }\end{array}$ & d.f & $\begin{array}{c}\text { P value } \\
\text { (Fishers } \\
\text { exact) }\end{array}$ & $\begin{array}{c}\text { OR } \\
\text { (95\% C.I) }\end{array}$ \\
\cline { 1 - 5 } Male & $27(36.5)$ & $47(63.5)$ & 74 & & & & 3.4 \\
Female & $4(14.3)$ & $24(85.7)$ & 28 & 3.7 & 1 & 0.032 & $(1-11)$ \\
\hline Total & $31(30.4)$ & $71(69.6)$ & 102 & & & & \\
\hline
\end{tabular}

Table 3: Association between parental consumption of alcohol and early onset of alcohol use (before 18 years)

\begin{tabular}{|lcccccc|}
$\begin{array}{l}\text { Parents } \\
\text { drinking }\end{array}$ & \multicolumn{2}{c}{ Drinking onset } & $\begin{array}{c}\text { Total } \\
\text { (N) }\end{array}$ & $\begin{array}{c}\text { Chi } \\
\text { square } \\
\text { value }\end{array}$ & $\begin{array}{c}\text { P } \\
\text { value }\end{array}$ & $\begin{array}{c}\text { OR } \\
\text { (95\% CI) }\end{array}$ \\
\cline { 1 - 3 } Yes & $24(37.5)$ & $40(62.5)$ & 64 & & & \\
No & $7(18.4)$ & $31(81.6)$ & 28 & 4.1 & 0.03 & $(1.01-6.96)$ \\
\hline Total & $31(30.4)$ & $71(69.6)$ & 102 & & & \\
\hline
\end{tabular}


Table 4: Distribution of binge drinking pattern by gender.

\begin{tabular}{|c|c|c|c|c|c|c|c|}
\hline \multirow[b]{2}{*}{ Sex } & \multicolumn{3}{|c|}{ Binge drinking } & \multirow{2}{*}{$\begin{array}{c}\text { Chi } \\
\text { square } \\
\text { value }\end{array}$} & \multirow[b]{2}{*}{ d.f } & \multirow{2}{*}{$\begin{array}{l}\text { P value } \\
\text { (Fisher } \\
\text { exacts) }\end{array}$} & \multirow{2}{*}{$\begin{array}{c}\text { Odds ratio } \\
\text { (95\% C.I) }\end{array}$} \\
\hline & Yes n (\%) & No n (\%) & Total N & & & & \\
\hline Male & $32(56.1)$ & $25(43.9)$ & 57 & \multirow{3}{*}{3.7} & \multirow{3}{*}{1} & \multirow{3}{*}{0.053} & \multirow{3}{*}{$\begin{array}{c}8.9 \\
(1.0-77.5)\end{array}$} \\
\hline Female & $1(12.5)$ & $7(87.5)$ & 8 & & & & \\
\hline Total & $33(50.8)$ & $32(49.2)$ & 65 & & & & \\
\hline
\end{tabular}

to be significantly associated with male gender (p-value: 0.05, OR: 8.9, 95\%CI: 1-77.5), where on average male consume about 3.5 standard drink and female consume about 1.8 standard drink in one occasion (Table 4). Additionally early onset of drinking before 18 years was also found to be significantly associated with binge drinking pattern (p-value: <0.001, OR: 9.5, 95\% CI: 2.7-33.3) (Table 5). On assessing the pattern of drinking using AUDIT score, $61(70.1 \%)$ of current drinker were found to consume alcohol in mild to moderate amount with (AUDIT score <8), $21(24.1 \%)$ were found to be harmful/hazardous drinker with (AUDIT score $\geq 8)$, and $5(5.7 \%)$ were found to be alcohol dependent with (AUDIT score >19) (Table 6). Initiating alcohol before 18 years was also found to be significantly associated with alcohol dependence (p-value: 0.002), however age of onset didn't traced out as a risk factor for alcohol dependence (0R: 0.8, 95\%CI: 0.67-0.97) (Table 7).

Among the current drinker almost one fourth (24\%) reported that they have visited to hospital in last 12 month due to alcohol related problems like gastroenterology/ hepatology problem, cardiovascular problems,

Table 5: Association between age of initiation of drinking and binge drinking

\begin{tabular}{|c|c|c|c|c|c|c|c|}
\hline \multirow{2}{*}{ Initiating drinking } & \multicolumn{3}{|c|}{ Binge drinking } & \multirow{2}{*}{$\begin{array}{c}\text { Fisher's } \\
\text { exact } \\
\text { value }\end{array}$} & \multirow{2}{*}{ d.f } & \multirow{2}{*}{$\begin{array}{l}\text { P value } \\
\text { (fisher's } \\
\text { exact) }\end{array}$} & \multirow{2}{*}{$\begin{array}{c}\text { Odds } \\
\text { ratio } \\
\text { (95\% C.I) }\end{array}$} \\
\hline & Yes n (\%) & Non (\%) & Total N & & & & \\
\hline Before legal drinking age & $19(82.6)$ & $4(17.4)$ & 23 & \multirow{3}{*}{14.4} & \multirow{3}{*}{1} & \multirow{3}{*}{$<0.001$} & \multirow{3}{*}{$\begin{array}{c}9.5 \\
(2.7-33.3)\end{array}$} \\
\hline After legal drinking age & $14(33.3)$ & $28(66.7)$ & 42 & & & & \\
\hline Total & $33(50.8)$ & $32(49.2)$ & 65 & & & & \\
\hline
\end{tabular}

Table 6: Alcohol drinking pattern assessed by AUDIT Score.

\begin{tabular}{|c|c|c|c|c|c|c|}
\hline \multirow{2}{*}{ Alcohol drinking pattern } & \multicolumn{3}{|c|}{ Sex } & \multirow{2}{*}{$\begin{array}{l}\text { Chi square value } \\
\text { (likelihood ratio) }\end{array}$} & \multirow{2}{*}{ d.f } & \multirow{2}{*}{ P value } \\
\hline & Male $\mathrm{n}(\%)$ & Female $\mathrm{n}(\%)$ & Total $(\mathrm{N})$ & & & \\
\hline $\begin{array}{l}\text { Mild to moderate } \\
(\text { AUDIT < 8) }\end{array}$ & $45(73.8)$ & $16(26.2)$ & 61 & & & \\
\hline $\begin{array}{l}\text { Harmful/Hazardous } \\
\text { (AUDIT } \geq 8)\end{array}$ & $19(90.5)$ & $2(9.5)$ & 21 & 5.3 & 2 & 0.071 \\
\hline $\begin{array}{l}\text { Alcohol dependence } \\
\text { (AUDIT > 19) }\end{array}$ & $5(100.0)$ & $0(0.0)$ & 5 & & & \\
\hline Total & $69(79.3)$ & $18(20.7)$ & 87 & & & \\
\hline
\end{tabular}

Table 7: Association between Alcohol Dependence and Age of onset of drinking.

\begin{tabular}{|lcccccc|} 
Initiation of & \multicolumn{3}{c}{ Alcohol Dependence } & Chi square & value & OR \\
Drinking & Yes n (\%) & No n (\%) & Total N (\%) & (Fishers exact) & value & (95\%CI) \\
\cline { 1 - 4 } Before legal age & $5(100.0)$ & $21(25.6)$ & $26(29.9)$ & & & \\
After legal age & $0(0.0)$ & $61(74.4)$ & $61(70.1)$ & 9.1 & 0.002 & $(0.67-0.97)$ \\
\cline { 1 - 4 } Total & $5(100.0)$ & $82(100.0)$ & $87(100.0)$ & & & \\
\hline
\end{tabular}




\begin{tabular}{|c|c|c|c|c|c|c|}
\hline \multirow[t]{2}{*}{ Drinking onset } & \multicolumn{2}{|c|}{$\begin{array}{l}\text { Hospital visit due to } \\
\text { alcohol related problem }\end{array}$} & \multirow{2}{*}{$\begin{array}{l}\text { Total } \\
\text { (N) }\end{array}$} & \multirow{2}{*}{$\begin{array}{l}\text { Chi square } \\
\text { value }\end{array}$} & \multirow{2}{*}{$P$ value } & \multirow{2}{*}{ OR (95\% CI) } \\
\hline & Yes n (\%) & No $n(\%)$ & & & & \\
\hline Before 18 years & $13(50)$ & $13(50)$ & 26 & \multirow[b]{3}{*}{13.5} & \multirow[b]{3}{*}{$<0.001$} & \multirow{3}{*}{$6.6(2.2-19.3)$} \\
\hline After 18 years & $8(13.1)$ & $53(86.9)$ & 61 & & & \\
\hline Total & $21(24.1)$ & $66(75.9)$ & 87 & & & \\
\hline \multirow{2}{*}{ Binge drinking } & \multicolumn{2}{|c|}{$\begin{array}{l}\text { Hospital visit due to } \\
\text { alcohol related problem }\end{array}$} & \multirow[t]{2}{*}{ Total (N) } & \multirow{2}{*}{$\begin{array}{l}\text { Chi square } \\
\text { value }\end{array}$} & \multirow[t]{2}{*}{$P$ value } & \multirow[t]{2}{*}{ OR (95\% CI) } \\
\hline & Yes n (\%) & No n (\%) & & & & \\
\hline Yes & $15(45.5)$ & $18(54.5)$ & 33 & & & \\
\hline No & $2(6.2)$ & $30(93.8)$ & 32 & 10.9 & $<0.001$ & $12.5(2.6-61.10$ \\
\hline Total & $17(26.2)$ & $48(73.8)$ & 65 & & & \\
\hline \multirow{2}{*}{$\begin{array}{l}\text { Alcohol } \\
\text { dependence }\end{array}$} & \multicolumn{2}{|c|}{$\begin{array}{l}\text { Hospital visit due to } \\
\text { alcohol related problem }\end{array}$} & Total (N) & \multirow{2}{*}{$\begin{array}{l}\text { Chi square } \\
\text { value }\end{array}$} & \multirow[t]{2}{*}{$P$ value } & \multirow[t]{2}{*}{ OR (95\% CI) } \\
\hline & Yes n (\%) & No $n(\%)$ & & & & \\
\hline Yes & $5(100.0)$ & $0(0.0)$ & 5 & \multirow{3}{*}{16.7} & \multirow{3}{*}{$<0.001$} & \multirow{3}{*}{$5.1(3.3-7.9)$} \\
\hline No & $16(19.5)$ & $66(80.5)$ & 82 & & & \\
\hline Total & $21(24.1)$ & 66 (75.9) & 87 & & & \\
\hline
\end{tabular}

self-inflicting injuries, accidents, CNS related problems, alcoholic psychosis etc. Interestingly hospital visit was more among those who initiate drinking before 18 years compared to those initiating drinking after 18 years ( $\mathrm{p}$-value: $<0.001$, OR: 6.63, 95\% CI: 2.7-19.3). Hospital visit was also significantly associated with binge drinking (p-value: <0.001, OR: 12.5\%, 95\% CI: 2.6-61.1) and alcohol dependence (p-value: 0.001, OR: 5.1, 95\%CI: 3.3-7.9) where binge drinker and dependent drinker were more likely to visit hospital for alcohol related problems compared to non binge drinker and those who drink in mild to moderate amount (Table 8).

\section{DISCUSSION}

In the present study, more than half of the respondents $(53.7 \%)$ had ever consumed alcohol in their life time. Prevalence of current drinker was found to be $45.8 \%$ and almost one third (34.2\%) had consumed alcohol within past 30 days. These rates are two times more than the report of national average (Ever consumed alcohol: 26.5\%, Current drinker: 22\%, Drinker within past 30 days: $17.4 \%$ ), but was lower than that of report from Bhaktapur by Maharjan PL and Magar KT (ever consumed alcohol: $67 \%$ and current drinking: 56\%), and from report of Manandhar $\mathrm{N}$ et al. (ever consumed alcohol: $73.8 \%$, current drinker: $62.8 \%)^{4,10,11}$ In contrast, the prevalence was bit lower in the study conducted in squatter of Kathmandu by
Thapa $\mathrm{P}$ et al. (39.8\% current drinker), and in Western Nepal 35.6\% (according to Adhikari TB et al). ${ }^{12,13}$ This shows a marked variation in the prevalence of alcohol consumption between the regions within a country, which could be due to the variation in the environmental factors, ethnicity, socio-demographic and economic factors between place to place, different level of accessibility and availability of alcoholic products, methodological difference and nature of the sample like sampling population characteristics and timeline.

In this study, the mean age of initiation of drinking was $20 \pm 4.3$ years. An earlier age of initiation was observed in study by Maharjan PL and Magar KT in 2017 which was 17 years. ${ }^{10}$ Such variation could be due to the nature of sample enrolled in that study where study was conducted only among the youth aged between 15-25 years. In Nepal, the legal age of alcohol drinking is 18 years. ${ }^{10}$ The present study showed that $30.4 \%$ drinker had initiated consuming alcohol before legal drinking age which was predominant among male $(36.5 \%)$ than female (14.3\%). In contrast, a very high percentage of drinkers (69.6\%) had initiated drinking before legal age in a study conducted among youth of Bhaktapur by Maharjan PL and Magar KT. ${ }^{10}$ Manandhar $\mathrm{N}$ et al. also reported that the majority of the drinker initiated drinking before legal age among the respondent of Bhimtar, Sindupalchowk. ${ }^{11}$ This may be due to their study setting and sample population with a high majority of persons from ethnic groups 
where alcohol is used traditionally and have a cultural practice of early initiation of alcohol consumption.

In this study, half of the current drinker of past 30 days (50.8\%) reported binge drinking behaviour. More were among male (56.1\%) then female (12.5\%) which was statistically significant with the gender ( $p$ value $<0.05$ ). This finding was consistent with the finding from study of Maharjan PL and Magar KT where $49.5 \%$ were binge drinker and majority were male $(47.6 \%)$ than female $(1.9 \%){ }^{10}$ In contrast to it, a very high prevalence of binge drinking (70\%) was reported by Adhikari TB et al. in Western Nepal, where male consumed $8.8 \pm$ 0.3 drinks and female consume $4.4 \pm 0.3$ drinks on average in one occasion. ${ }^{13}$ In contrast, the present study shows that the average drinks consumed in one occasion by male and female was $3.5 \pm 1.4$ and $1.8 \pm 1.4$ drinks respectively. Such a huge variation in binge drinking would be due to variation in sample size and nature of sample.

Age of initiation of drinking was strongly associated with binge drinking pattern in this study ( $p$ value: $<0.001$ ). Those who initiate drinking early in life before 18 years are 9.5 times more likely to get into binge drinking behaviour than those who initiate drinking later in life. Similar finding was reported by Isorna FC et al. which reported that early age of onset of alcohol use had a higher risk (OR: 4.8) towards getting into Heavy Episodic Drinking (HED) and Risky Consumption (RC). ${ }^{14}$ Similarly the study conducted in US by Hingston RW et al revealed that those who began drinking at younger age (before 18 years) were more likely to experience alcohol dependence and also alcohol related problem during adult life. ${ }^{15}$ According to Liang $\mathrm{W}$ et al, binge drinking was significantly higher among those who started consuming alcohol before 18 years and conversely, having first consumed alcohol at or after 25 years reduced the risk of heavy alcohol use. ${ }^{16}$

The study showed that among the current drinker, almost quarter (24.1\%) were Harmful/ Hazardous alcohol user (AUDIT score $\geq 8$ ), while $5.7 \%$ were Alcohol Dependent (AUDIT score $>19$ ) and majority $(70.1 \%)$ were mild to moderate alcohol user (AUDIT <8). These findings were consistent with the findings from the study conducted in 2013 by Luitel NP et al. which reported the prevalence of Hazardous drinker was 22\% and Alcohol Dependence 5.3\%. ${ }^{17}$ Similar findings were also reported in India in 2015 by Rathod SD et al. where prevalence of Hazardous drinker was $33.2 \%$ and Dependent drinker $5.5 \% .{ }^{18}$ However the prevalence of alcohol dependence in the present study was found to be lower than the general population in the city of Dharan in eastern Nepal (25.8\%) as per the study by Jhingan HP et al. ${ }^{3}$

The present study shows almost one fourth (24\%) of the alcohol user had visited the hospital in last 12 months due to alcohol related problems. Hospital visit were also more among binge drinker, dependent drinker, and those who initiate drinking at early age. A study which was conducted among culturally diverse population over several European and American countries reported that almost one fourth (23\%) of the harmful alcohol user had experience at least one alcohol related problem, that signifies a strong co-relation between drinking behaviour and alcohol related problems. ${ }^{19}$ Hence the onset of alcohol use before 18 years would therefore increase the risk of alcohol use disorder ultimately leading to alcohol related harmful effects, so abstinence from alcohol until the age of 18 years would be likely to reduce alcohol related harm.

Parental consumption of alcohol at home would stand as a possible influencing factor for the drinker to initiate drinking at an early age (p-value: 0.03, OR: 2.7, 95\%CI: 1.01-6.9) as per finding from present study. However the exact causal mechanism of association between age of onset of alcohol and alcohol use disorder is not fully understood. It may be plausible that starting to use alcohol before 18 years directly increase the risk of developing heavy alcohol use behaviour. The risk of developing heavy drinking habit before 18 years is nil for a person who start drinking after 18 years, however the risk may exceed for person who start drinking before 18 years. $^{20}$ It is also important that parents attitudes and behaviour during their children's initial exposure to alcohol may have an effect on their future consumption pattern. ${ }^{21}$ Moreover adolescents are more likely to engage in sensation seeking and risk taking behaviours compared to adult thereby given higher access to alcohol and increased risk of frequent heavy alcohol in young age. ${ }^{22}$

The presentstudyhelped to assess the magnitude and pattern of alcohol consumption habits in the population of Jhaukhel community. It also allowed us to identify that alcohol use/abuse was associated with various factors including age of drinking onset, parental consumption of alcohol. These findings emphasize the importance of the study to further explore the magnitude of the morbidity pattern of the harmful alcohol consumption. Understanding the prevalence of alcohol use and pattern of consumption habits is essential to establish surveillance actions and assess the impact of future intervention programme. Identifying 
the most vulnerable group of hazardous and dependent drinker may guide for the more effective control actions and harm reduction strategies. Additionally the findings from this study are also closely relevant to legislation on minimum drinking age.

\section{ACKNOWLEDGEMENT}

This paper was published from the thesis submitted to Kathmandu University (KU) for the partial fulfilment of MD in community medicine. I would like to express my heartfelt gratitude to 'Nepal Medical College - Institutional Review Committee' (NMC-IRC) for granting me the ethical approval to conduct this study. I would also like to thank all the residents of Jhaukhel, Bhaktapur for their willingness to participate in this study.

\section{Conflict of interest: None}

Source of research fund: None

\section{REFERENCES}

1. WHO, Global status report on alcohol and health (2014).

2. Park K. Medicine and Social Science. Park's Textbook of Preventive and Social Medicine $\left(24^{\text {th }}\right.$ edition). M/s Banarsidas Bhanot Publisher 2017: 734.

3. Jhingan HP, Shyangwa P, Sharma A, Prasad KM, Khandelwal SK. Prevalence of alcohol dependence in a town in Nepal as assessed by the CAGE questionnaire. Addiction 2003; 98: 339-43.

4. Aryal K, Neupane S, Mehata S, et al. Noncommunicable disease risk factor: STEPS survey Nepal, 2013, Kathmandu: Nepal Health Research Council 2014.

5. Lim SS, Vos T, Flaxman AD et al. A comparative risk assessment of burden of disease and injury attributable to 67 risk factors and risk factor cluster in 21 regions, 1990-2010: A systematic analysis for the global burden of disease study 2010. Lancet 2012: 380: 2224-60.

6. Dawson DA, Goldstein RB, Chou SP, Ruan WJ, Grant BF. Age at first drink and the first incidence of adult-onset DSM-IV alcohol use disorder. Alcoholism 2008; 32: 2149-60.

7. Diemen LV, Bassani DG, Fuchs SC, Szobot CM, Pechansky F. Impulsivity, age of first alcohol use and substance use disorder among male adolescents: A population based case-control study. Addiction 2008; 103: 1198-205.

8. McGue M, Iacono WG, Legrand LN, Elkins I. Origin and consequence of age at first drink II: Familial risk and heritability. Alcohol Clin Exp Res 2001; 25: 1166-73.

9. Saunder JB, Aasland OG, Babor TF et al. Development of Alcohol Use Disorder Identification Test (AUDIT): WHO collaborative project on early detection of person with harmful alcohol consumption-II. Addiction 1993; 88: 791803.

10. Maharjan PL, Magar KT. Prevalence of alcohol consumption and factors associated with alcohol use among the youth of Suryabinayak Municipality, Bhaktapur. J Pharma Care Health Sys 2017; 4: 168.

11. Manandhar N, Shrestha MV, Joshi SK. Prevalence of alcohol consumption and knowledge about alcohol at Bhimtar, Sindupalchowk. J Nepal Med Assoc 2017; 56: 293-7.
12. Thapa P, Mishra SR, Pandey AR et al. Prevalence and predictors of alcohol consumption among the squatter of Kathmandu Valley. J Nepal Health Res Counc 2016; 14: 18-26.

13. Adhikari TB, Rijal A, Kallestrup $\mathrm{P}$ et al. Alcohol consumption pattern in western Nepal: Findings from the COBIN baseline survey. BMC Psychiatr 2019; 19: 283.

14. Isorna FC, Corral M, Parada M, Cadaveira F. Factors associated with risky consumption and heavy episodic drinking among Spanish University students. J Studies Alcohol Drugs 2008; 69: 308-12

15. Hingston RW, Heeren T, Winter MR. Age at drinking onset and alcohol dependence. Age at onset, duration and severity. Arch Pediatr Adolesc Med 2006; 160: 739-46. doi: 10.1001/ archpedi.160.7.739

16. Laing W, Chikritzhs T. Age at first use of alcohol and risk of heavy alcohol use: A population based study. Biomed Research International 2013; 5. Article ID: 721761. doi.org/10.1155/2013/721761

17. Luitel NP, Jordan M, Murphy A, Roberts B, Cambridge JM. Prevalence and pattern of hazardous and harmful alcohol consumption assessed using the AUDIT among Bhutanese Refugees in Nepal. Alcohol Alcohol 2013; 48: 34955

18. Rathod SD, Nadkarni A, Bhana A, Shidhay R. Epidemiological features of alcohol use in rural India: A population-based cross-sectional study. Brit Med J Open 2015; 5: e009802

19. Saunders JB, Aasland OG, Amundsen A, Grant M. Alcohol consumption and related problems among primary health care patients: WHO collaborative project on early detection of person with harmful alcohol consumption. Addiction 1993; 88: 349-62

20. Swendsen J, Burstein M, Case B et al. Use and abuse of alcohol and illicit drugs in US adolescents: Result of national co-morbidity survey- Adolsecent supplement. Archives of general psychiatry 2012; 69: 390-98

21. Kamro KA, Maldonado-Molina MM, Tobler AL, Bonds JR, Muller KE. Effects of home access and availability of alcohol on young adolescents alcohol use. Addiction 2007; 102: 1597-608

22. Liang W, Chikritzhs T. Alcohol consumption and health status of family member: Health impact without ingestion. Internal Med J 2013; 43: 1012-6. 